\title{
О ВОЗМОЖНОСТИ ПРИМЕНЕНИЯ МЕТОДА ВОСХОЖДЕНИЯ ОТ АБСТРАКТНОГО К КОНКРЕТНОМУ В ПЕДАГОГИКЕ
}

\begin{abstract}
В.К. Буряк
Возросшие задачи, стоящие перед образованием, воспитанием и обучением в связи с социальным и научно-техническим прогрессом, требуют от педагогической науки поднятия ее исследований на новую, более высокую ступень. На наш взгляд, большую помощь в этом отношении педагогике может оказать диалектика, в частности, такой ее эффективный метод, как восхождение от абстрактного к конкретному. Нужно отметить, что в последнее время представители педагогической науки в своих исследованиях не так часто обращаются к диалектике, мало используют ее в качестве мировоззрения и методологии научного познания. А между тем она помогла бы решить многие проблемы, над которыми бьется вот уже в продолжении многих десятилетий наша педагогическая мысль.

В настоящей статье ставится цель обосновать правомерность и необходимость применения в педагогике диалектического метода восхождения от абстрактного к конкретному.

Прежде всего, необходимо отметить, в каком смысле в статье будут использоваться категории «абстрактное» и «конкретное», а также как понимается суть данного метода. Это тем более необходимо сделать, поскольку в философской и педагогической литературе однозначного мнения по этим вопросам нет.

Иногда под абстрактным понимают нечто отвлеченное, и тогда, естественно, сферой абстрактного считают мышление, потому что отвлеченное может быть только в мышлении. В таком случае конкретным будет действительность. Конечно, можно и так понимать эти категории. Однако К. Маркс, разбирая в предисловии к книге «К критике политической экономии» категории абстрактного и конкретного, берет их в более широ-
\end{abstract}

Актуальні проблеми духовності

(Відп. ред.: Я.В. Шрамко)

Кривий Ріг (2005), 229-234 
ком плане. Абстрактное К.Маркс определяет как то, что односторонне, неполно, что является в познавательном отношении бедным. Абстрактное выступает одной стороной какого-либо предмета. Конкретное же, напротив, есть многостороннее и богатое. «Конкретное, - пишет К. Маркс, потому конкретно, что оно есть синтез многих определений, следовательно, единство многообразногого» ${ }^{1}$. Следовательно, и абстрактное, и конкретное существуют как в мышлении, так и в действительности, которая отражается в мышлении.

Абстрактное и конкретное образуют диалектическое противоречие. Отрицая друг друга, находясь в отношениях противоположности, они в то же время предполагают, дополняют друг друга. Абстрактное отрицает конкретное, ибо есть лишь одна сторона предмета. Конкретное же отрицает абстрактное, поскольку образует все стороны предмета, совокупность всех его характеристик. Одно есть органическое целое, другоевсего лишь момент этого целого.

Другая сторона противоречия данных категорий - их единство, состоящее в том, что абстрактное и конкретное неотделимы друг от друга. Абстрактное всегда существует в связи с конкретным, немыслимо без него и, равным образом, конкретное существует лишь там, где имеется абстрактное. Абстрактное и конкретное, следовательно, - соотносительные категории, взаимно определяющие друг друга. Нет абсолютно абстрактного момента, но нет и абсолютно конкретного. Признак, который мы считаем абстрактным в данной связи, может в другой связи выступать как конкретный, и наоборот. Следовательно, абстрактное и конкретное можно противопоставлять друг другу лишь в очень узких пределах. В широких же масштабах их противопоставлять нельзя, ибо они выступают полюсами одного и того же единого целого. Всякая попытка брать абстрактное и конкретное оторвано друг от друга ведет неизбежно к метафизике.

Поскольку абстрактное и конкретное существуют в единстве, постольку и в процессе познания они должны рассматриваться в единстве. Познавая предмет, мы всегда должны иметь в виду, что он есть связь, единство абстрактных и конкретных моментов. Правда, так как наше познание есть процесс, то оно не может сразу схватить в предмете абстрактное и конкретное одновременно. Процесс предполагает, что мы изучаем сначала одну сторону, затем другую и т.д. K тому же надо учитывать в познания две ступени: чувственную и рациональную.

Таким образом, весь процесс познания в плане интересующих нас категорий абстрактного и конкретного схематически выглядит так: конкретное в реальной действительности $\rightarrow$ абстрактное $\rightarrow$ конкретное в мышле-

\footnotetext{
${ }^{1}$ Маркс К. Введение / Из экономических рукописей 1857-1858 гг. // Маркс К. и Энгельс Ф. Соч. Т. 12. - С. 727
} 
нии. Он состоит из двух этапов: первый этап начинается с конкретного в реальной действительности и заканчивается абстрактным, второй этап начинается тем, чем заканчивается первый этап, т.е. абстрактным, и заканчивается конкретным, но уже в мышлении. Второй этап есть воспроизведение реально конкретного в теоретическом мышлении, это восхождение от абстрактного к конкретному. Метод восхождения от абстрактного к конкретному есть лишь способ, при помощи которого мышление усваивает себе конкретное, воспроизводит его духовно как конкретное.

Общим законом рассмотрения предмета, а следовательно, и расположения категорий при его исследовании способом восхождения от абстрактного к конкретному является следующий: наиболее абстрактная категория должна предшествовать наименее абстрактной или, иначе, более конкретная категория должна следовать за менее конкретной.

В способе восхождения от абстрактного к конкретному исследователь применяет определенные методы и приемы изучения материала. Безусловно, это прежде всего такие обычные методы и приемы как обобщение и абстрагирование, индукция и дедукция, анализ и синтез и т.д. Но не об этих методах в данном случае идет речь, потому что не они характеризуют специфику способа восхождения от абстрактного к конкретному, их можно встретить и в других способах исследования. Специфику же метода восхождения от абстрактного к конкретному образуют другие приемы, важнейшими из которых являются: приемы исследования противоречий, открытие закона и форм его проявления, метод логического и исторического, рассмотрение явлений в чистом виде и др.

Остановимся теперь на гносеологическом значении способа восхождения от абстрактного к конкретному. Это прежде всего есть способ воспроизведения предмета как единого и вместе с тем диалектически расчлененного целого. Его задача - воссоздать в теоретически последовательной форме целостную систему предмета. Восходя от абстрактного к конкретному, мы переходим от одной категории к другой, от низшей к высшей, выводим категории друг из друга. В результате создается целостная система связанных между собой категорий. Данная связь необходима, она исключает какую бы то ни было случайность, а тем более произвол.

Способ восхождения от абстрактного к конкретному, далее, делает науку, в которой он применяется, строго доказательной теорией, ибо каждое ее положение, каждая категория всегда доказывается, обосновывается. При этом следует подчеркнуть, что доказательство, специфически характерное для процесса восхождения, отличается от формального доказательства, о котором учит обычная логика, хотя это последнее и при осуществлении способа восхождения находит свое применение. Оно является по своему существу генетическим доказательством. 
В способе восхождения от абстрактного к конкретному по-особому ставится вопрос не только о доказательстве, но и об определении. Определение в обычном формально-логическом смысле (как дефиниция) отступает здесь на второй план. Главным является развитие самой сути дела.

Восходя от абстрактного к конкретному, исследователь вскрывает внутренние противоречия предмета, показывает, как эти противоречия возникают, в каких формах существуют и во что развиваются. Исследование противоречий предмета - главное в способе восхождения, потому что оно вскрывает источник диалектического развития и изменения. В этом также состоит одно из значений способа восхождения. При этом исследуются не только противоречия, но и развитие их, на что мы уже указывали.

Благодаря такому подходу в исследовательском мышлении воспроизводится сложная противоречивая система предмета, а сам предмет предстает как живое органическое целое. Раскрытие системы противоречий позволяет проникнуть в глубинную связь и сущность отношений предмета, что составляет главную ценность в познании.

Последнее, что мы хотим осветить в данной части статьи, это вопрос о возможностях применения способа восхождения от абстрактного к конкретному.

Чтобы решить данный вопрос, нужно исходить из следующей предпосылки. Каждая наука имеет свой предмет исследования, который носит диалектический характер. Из этого вытекает, что перед каждой наукой рано или поздно встает задача представить свой предмет как сложное диалектическое целое, а это можно осуществить лишь способом восхождения от абстрактного к конкретному. Исходя из сказанного, нетрудно заключить, что нет абсолютно ничего, что делало бы принципиально невозможным применение способа восхождения от абстрактного к конкретному в других науках. Нельзя согласиться с тем мнением, будто этот метод является специфическим для исследования исторически преходящих явлений.

Рассмотрим вопрос о возможности применения метода восхождения от абстрактного к конкретному в педагогической науке, в чем и состоит основная задача настоящей статьи.

Среди части педагогов существует скептическое отношение к возможности применения в педагогике метода восхождения от абстрактного к конкретному. При этом некоторые из них ссылаются на то, что педагогический процесс не является исторически преходящим процессом, а существует в продолжении всего времени существования человечества. Данный аргумент не является состоятельным. Дело не в том, преходящ исследуемый предмет или нет, вечно он существует или не вечно. Главное для метода восхождения от абстрактного к конкретному - чтобы пре- 
дмет, к которому он применяется, всегда находился в движении, изменении. А это в отношении педагогического процесса - предмета науки педагогики - бесспорный факт. Поскольку педагогический, учебно-воспитательный процесс развивается, он без всякого сомнения содержит в себе возможность применения к нему метода восхождения от абстрактного к конкретному.

В литературе по разбираемому вопросу можно встретить и другой взгляд. Считают, что надо различать педагогику как науку и педагогику как педагогический процесс (обучение и воспитание). К первой, притом взятой в ее историческом развитии, вполне можно применять метод восхождения, ко второму же, особенно в параметрах средней школы, он якобы совсем неприложим. Верно, конечно, что следует различать науку педагогику и педагогический процесс: первая есть всего лишь учение о втором. Однако это совсем не значит, будто, применяя в педагогике как науке метод восхождения от абстрактного к конкретному, мы не должны затрагивать самый ее предмет - процесс обучения и воспитания. Ведь педагогическая наука есть не что иное, как теория педагогического процесса, отражение (более или менее адекватное) его различных сторон.

Поэтому, строя педагогику методом восхождения от абстрактного к конкретному, мы неизбежно бросаем соответствующий взгляд и на педагогический процесс, более того, затрагиваем содержание и структуру последнего. K тому же нельзя сводить педагогику лишь к ее истории: помимо истории есть еще и теория педагогики, ее логика, которые не совпадают между собой. Метод восхождения от абстрактного к конкретному можно применять как в истории педагогики (этот аспект в настоящей статье не рассматривается), так и в ее теории, а также в анализе ее современного состояния (горизонтального среза).

Совершенно другой вопрос - можно ли реальный педагогический процесс, то есть, все преподавание в средней школе, все изложение материала (особенно в начальных классах) строить диалектическим методом восхождения от абстрактного к конкретному, начиная с введения самых общих, абстрактных понятий и постепенно переходя затем к понятиям предельно конкретным. На наш взгляд, этот вопрос не тождественнен вопросу о возможности применения в педагогике рассматриваемого метода. На него мы отвечаем отрицательно: неправильно переводить все преподавание в средней школе, особенно на начальной ее ступени, на использование метода восхождения от абстрактного к конкретному. И вообще этот метод нельзя абсолютизировать, как делают некоторые философы и педагоги, считая его единственной формой диалектического мышления. $\mathrm{K}$ чему приводит безграничное применение данного метода в обучении видно из последней перестройки преподавания математики в средней школе, отвергнутой педагогической практикой и справедливо осужденной авто- 
ритетными учеными-математиками нашей страны.

Следовательно, надо различать применение метода восхождения от абстрактного к конкретному: (а) в педагогике как науке, которая исследует педагогический процесс и (б) в преподавании учебных дисциплин в средней школе. Хотя, еще раз подчеркнем, первое так или иначе сказывается на втором, влияет на него, повышает его эффективность. Рассмотрение характера такого влияния может и должно составить предмет специального исследования.

Порой при рассмотрении обсуждаемой проблемы высказыватся и следующее соображение. Метод восхождения от абстрактного к конкретному есть метод построения науки на теоретическом ее уровне, когда преодолен уровень эмпиризма; педагогика же все еще находится на ступени эмпирического исследования и поэтому о применении в ней указанного метода речи быть не может. Мы не считаем правильной квалификацию достигнутого уровня развития педагогики в целом как эмпирического (хотя допускаем, что в ней эмпиризма еще немало). Но даже если допустить наличие у педагогики такого уровня, то отсюда еще не следует, будто он делает невозможным всякую попытку пользоваться в педагогике методом восхождения от абстрактного к конкретному. В самом деле, почему бы не решать одновременно две задачи: строить педагогику данным методом и поднимать ее тем самым с эмпирического уровня на теоретический? Такое совместное решение двух задач вполне возможно. Можно миновать некоторые предварительные этапы развития науки от эмпирической ступени к теоретической. Когда есть образец, не обязательно идти вперед медленно, методом проб и ошибок, проходя все этапы; можно двигаться и ускоренными темпами. Кстати, применение в педагогике метода восхождения от абстрактного к конкретному подскажет также, каким образом лучше всего достигнуть в ней более высокого теоретического уровня и что это, собственно, будет означать.

Подводя итог нашему рассмотрению, отметим, что пути и формы применения в педагогике метода восхождения от абстрактного к конкретному нуждаются в специальном обсуждении. В данной статье мы лишь сформулировали проблему в общем виде и наметили некоторые возможные подходы к ее рассмотрению. Весьма желательно, чтобы по этому вопросу высказались другие исследователи, прежде всего педагоги-теоретики. Проблема эта довольно сложна, и лишь коллективными усилиями педагогов, философов, логиков можно будет справиться с поставленной задачей: исследовать педагогический процесс методом восхождения от абстрактного к конкретному. 